DOI: $10.14451 / 1.186 .125$

\title{
РАЗРАБОТКА МЕТОДИКИ ПОВЫШЕНИЯ ЭФФЕКТИВНОСТИ ИСПОЛЬЗОВАНИЯ ВОДЫ НА ДЕЙСТВУЮЩИХ ПРОМЫШЛЕННЫХ ПРЕДПРИЯТИЯХ
}

\author{
(c) 2020 Табакова Анастасия Станиславовна \\ Санкт-Петербургский политехнический университет Петра Великого, Россия, Санкт-Петербург \\ (c) 2020 Новикова Ольга Валентиновна \\ Санкт-Петербургский политехнический университет Петра Великого, Россия, Санкт-Петербург
}

Все современные промышленные предприятия используют различные природные ресурсы для производства конечной продукции и хозяйственных нужд. Одним из таких ресурсов является вода. В 2017 году промышленными предприятиями в Российской Федерации за год было использовано 34,5 миллиардов тон воды [1], при этом недостаток питьевой воды для населения в засушливых регионах мира уже стал повсеместной проблемой, естественное воспроизводство в мире пресной питьевой воды идет существенно медленнее, чем потребление, также экологические катастрофы сокращают количество воды, которую мы можем использовать для потребления [2]. Более того, финансовая стоимость данного ресурса постоянно увеличивается. В связи с этим крайне актуально разработать методику по сокращению потребления воды для действующих промышленных предприятий, что приведет к сокращению воздействия промышленности на экологию, а также позволит достигнуть сокращения финансовых затрат и улучшит экономическую эффективность предприятий.

Ключевые слова: методика повышения эффективности, использование воды, промышленные предприятия, пять почему, корневая причина.

Цель: Разработать методику повышения эффективности использования воды на действующих промышленных предприятиях.

Объект: Промышленные предприятия, использующие воду в качестве конмпонента конечного продукта.

Предмет: Использование воды на промышленных предприятиях.

Задачи:

1. Разработка методики, позволяющей сократить потребление воды с учетом технологических особенностей предприятия.

2. Проведение апробации разработанной методики на примере действующего промышленного предприятия.

Предлагаемая авторами методика сокращения потребления воды состоит из 6 шагов (технических и аналитических мероприятий выполняемых в системе водоснабжения исследуемого промышленного предприятия). В рамках первого шага необходимо определить наибольшего потребителя воды на исследуемом промышленном предприятии. Для того чтобы это сделать необходимо детально изучить систему распределения и потребления воды на всем предприятии и далее, основываясь на данных с установленных расходомеров воды, определить наибольшего потребителя воды на предприятии, так как именно это позволяет получить наибольший результат от внедряемой методики.

На втором шаге для выбранного приоритетного потребителя необходимо провести текущие замеры по потреблению воды при помощи расходомеров. Расходомеры могут быть переносными или врезаемыми в трубопровод. Необходимо помнить, что при проведении замеров необходимо фиксировать данные по расходу воды в разных точках системы в один и тот же период времени с тем, чтобы эффект от потребления воды при разных производственных циклах на предприятии не влиял на данные в измерениях расхода воды. Чем большее количество расходомеров установлено, тем более четко могут быть определены места и причины потери воды. Поэтому рекомендуется устанавливать расходомеры после каждого технологического элемента в системе водопотребления. Данный подход является экономически затратным и не все предприятия готовы нести необходимые расходы на установку расходомеров после каждого потребителя воды. Минимальным необходимым требованием при реализации данной ме- 
тодики является наличие расходомеров на входе и выходе воды для изучаемого потребителя.

После того как собраны данные по замерам (минимальный рекомендуемый период должен выбираться в соответствии со спецификой деятельности предприятия) на третьем шаге необходимо проанализировать количественные потери воды между точками, в которых проводятся замеры. Таким образом, для расчета потери воды необходимо воспользоваться формулой 1.

Потеря воды = ((данные замера ближе к началу системы - данные замера на следующей точке учета) / данные замера ближе к началу системы) * $100 \%$

На основании полученных данных о потерях, выбираются места с наибольшими потерями воды и в рамках шага 4 проводятся действия по устранению причины потери при помощи аналитических инструментов определения корневых причин проблемы. К таким инструментам относятся:

- Пять почему [3] - анализ, позволяющий определить корневую причину проблемы, задавая вопрос «Почему» пять и более раз.

- Диаграмма Исикавы [4] - графический анализ причинно-следственных связей, который на основании группового поиска причин позволяет определить корневую причину в рамках следующих групп: человек, машина, материал, метод.

- Метод Киплинга [5] - анализ, основанный на описании феномена проблемы, за счет ответов на вопросы «что», «где», «когда», «кто», «какие тренды», «как».

Пятым шагом идет стандартизация, в рамках которой необходимо провести повторные замеры на участках системы водоснабжения, где производились изменения и зафиксировать новые значения потребления воды и рассчитать насколько изменились потери. В случае если сокращение потерь не соответствует ожидаемым результатам необходимо изучить систему водоснабжения повторно и найти ошибку при внедрении изменений. После подтверждения результатов ожидаемых улучшений необходимо зафиксировать как стандарт текущее потребление воды и определить периодичность для проверки расхода в данной точке (рекомендуется не реже один раза в год). Также необходимо убедиться, что внесены необходимые измене- ния во всю производственно-технологическую документацию, а именно: изменены процедуры обслуживания узлов оборудования, изменены технологические регламенты, созданы новые процедуры для сотрудников предприятия и т.д.

В рамках шестого шага необходимо выбрать следующего по приоритетности потребителя, то есть того, чье потребление воды является следующим по величине. Также в рамках данного шага необходимо проанализировать схожие участки, где возможна аналогичная потеря воды и в случае обнаружения сделать репликацию действия, показавшего положительный результат.

Таким образом, описанную выше методику, позволяющую сократить потребление воды на предприятии, можно представить в виде шагов, представленных на (Рис. 1).

Далее опишем апробацию разработанной методики на примере промышленного предприятия по производству товаров личной гигиены (шампуни, гели для душа, кондиционеры), товаров по уходу за домом (чистящие средства) и дезодорантов.

В рамках первого шага авторы изучили систему распределения воды на предприятии (Рис. 2).

Далее по перечисленным потребителям была получена со счетчиков информация по потреблению воды за 2017 год и было определено количественное распределение расхода воды на предприятии, представленное на (Рис. 3).

Таким образом по результатам первого шага было выявлено, что приоритетным потребителем для выбранного промышленного предприяия является производство.

Второй шаг авторы начали с анализа расположения уже установленных расходомеров потребления воды (Рис. 4).

В рамках изучаемого предприятия вся вода, используемая на производстве предварительно проходит дополнительную очистку через систему различных фильтров. Суммарно вся система фильтрации приводила к 20\% потерям воды, из которых 15\% терялось на фильтре «обратный осмос». Это процесс очистки воды, в котором, при определённом давлении, вода проходит через полупроницаемую мембрану из более концентрированного в менее концентрированный раствор, то есть в обратном для осмоса направлении. При этом мембрана пропускает воду, но не пропускает некоторые растворённые в ней вещества [6]. Другие 20\% из общих потерь воды промышленного предприятия терялись в рамках 


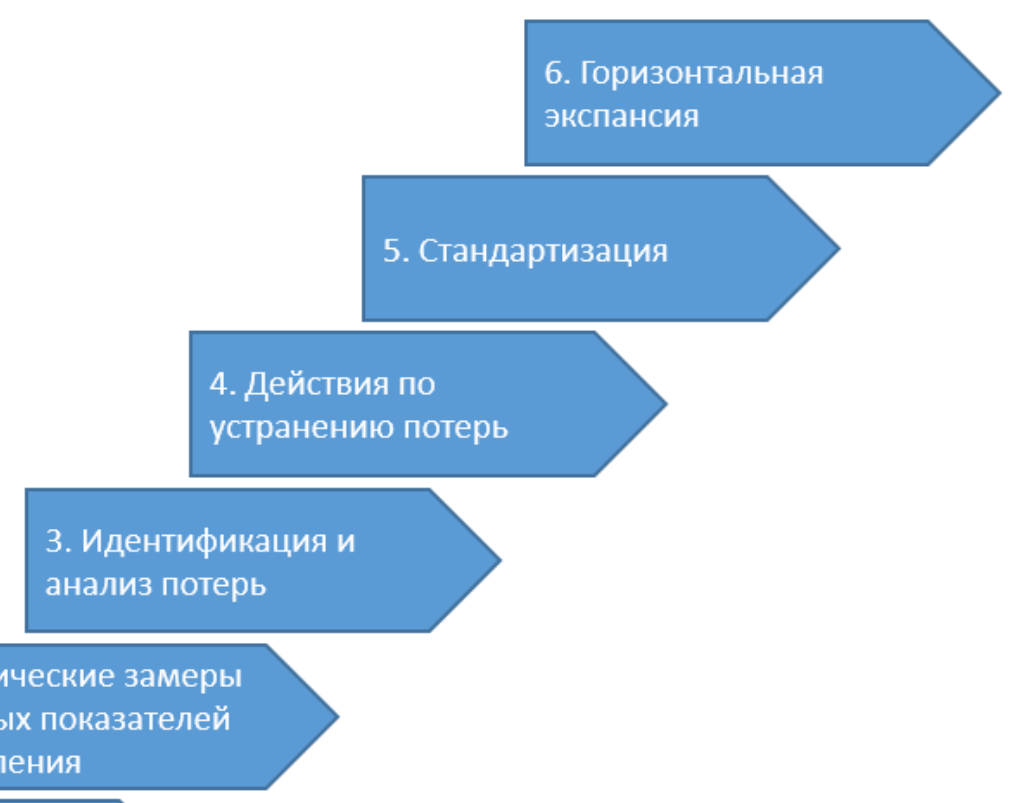

1. Определение

наибольшего

потребителя

Рuc. 1. Методика сокращения потерь воды на промышленном предприятии

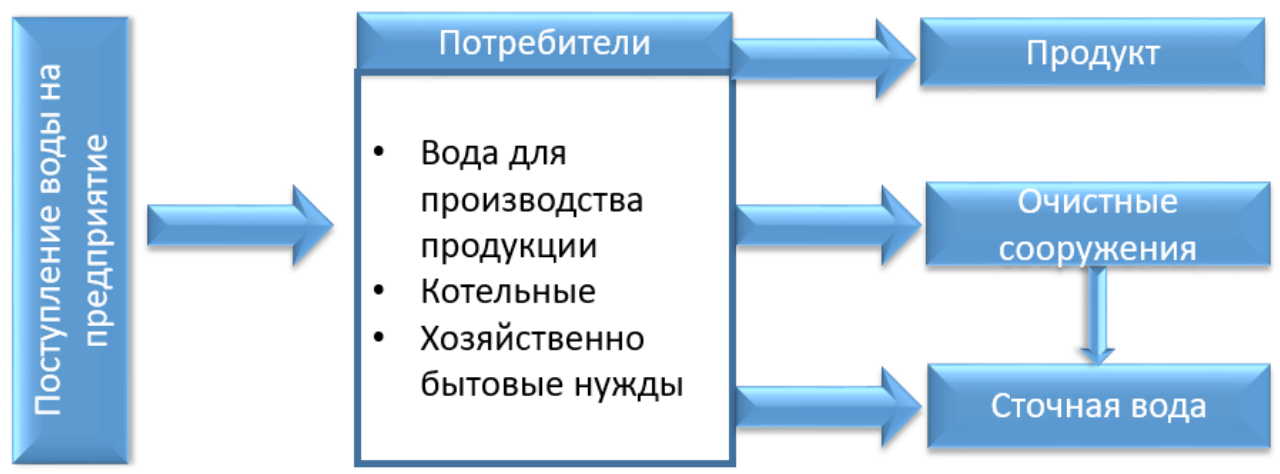

Puc. 2. Система распределения воды на исследуемом предприятии

\section{4,777}

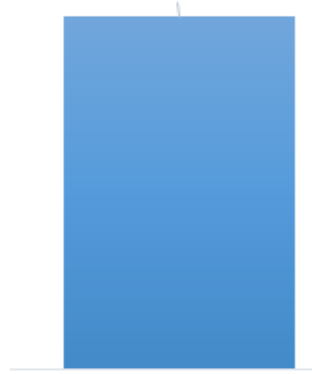

18,981

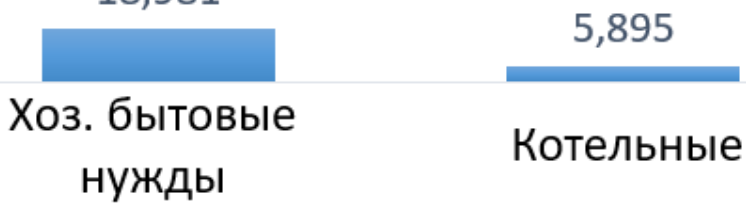

Puc. 3. Распределение потребления воды по потребителям за 2017 год, м $^{3}$ 


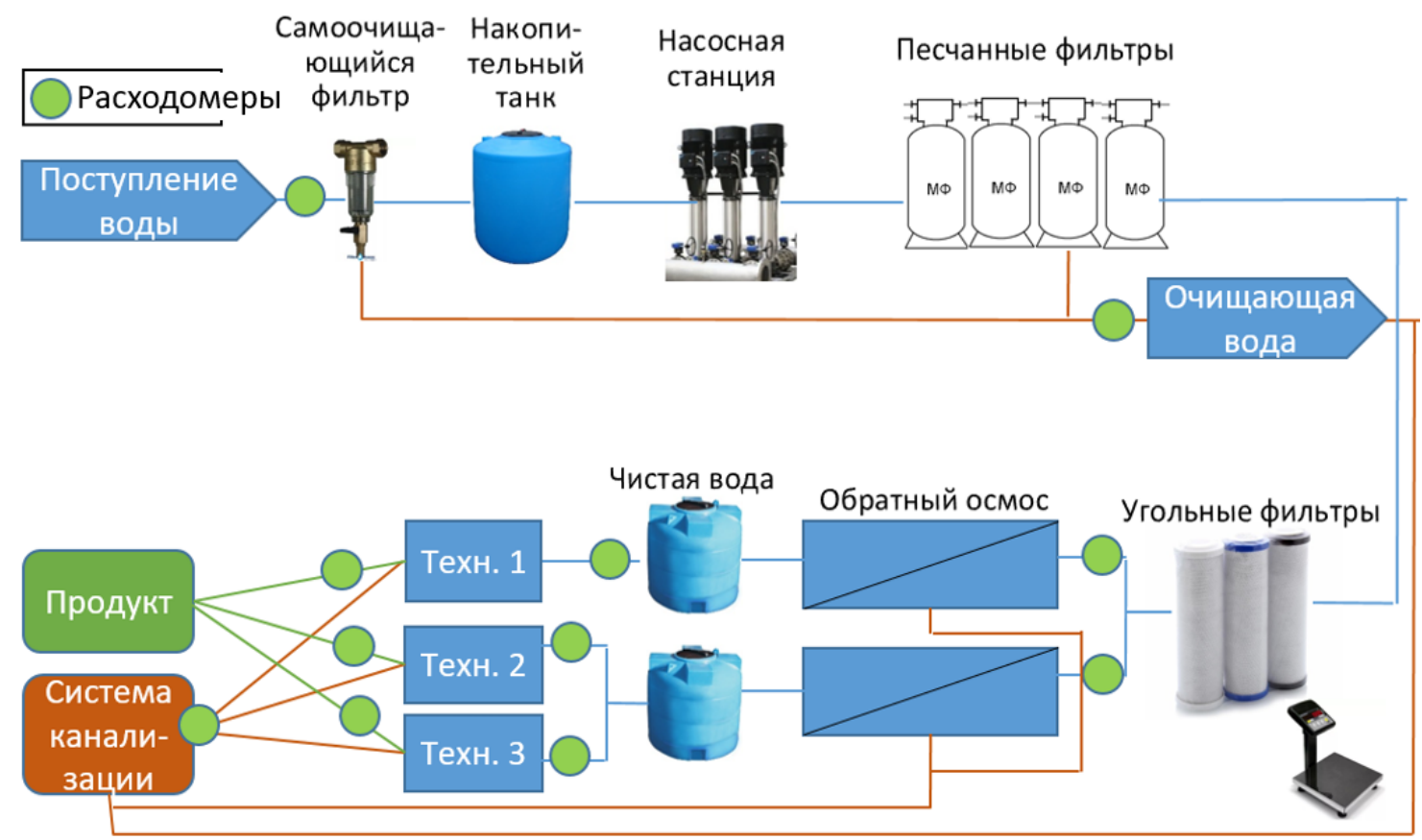

Puc. 4. Расположение расходомеров потребления воды на системе водоснабжения производства

производственного процесса, из которых 11\% составляли потери на промывке оборудования.

Определив ключевые источники потерь воды, авторы перешли к определению и внедрению действий, необходимых для устранения данных потерь. Было выявлено, что 15\%-е потери на «обратном осмосе» происходили из-за повышенного загрязнения мембран и их нерегулярной чистки. Авторы провели анализ эффективности работы системы фильтрации и определи критический объем воды, который должен пройти через фильтр для появления необходимости в очистке мемран обратного осмоса. Таким образом, чистка мембран стала происходить после $25000 \mathrm{~m}^{3}$, а не после $60000 \mathrm{~m}^{3}$ как было определено до проведенного анализа. В связи с тем, что технологический процесс чистки мембраны занимает 3 часа для проведения данной работы не потребовалось нанимать дополнительный персонал или нести дополнительные затраты. Данная технологическая операция стала проводиться в рамках регулярного технического обслуживания производственного оборудования во время технологической сервисной остановки.

11 процентов воды, которые терялись при промывках производственного оборудования и потребовали использования применения аналитического инструмента «Пять почему» для 1 технологии из трех, на которой эта потеря воды

Таблица 1. «Пять почему» анализ для потери воды при промывках обордования

\begin{tabular}{|c|c|c|c|c|c|}
\hline Почему 1 & Почему 2 & Почему 3 & Почему 4 & Почему 5 & Почему 6 \\
\hline \multirow[t]{2}{*}{$\begin{array}{l}\text { При промывках } \\
\text { оборудования } \\
\text { теряется больше } \\
\text { воды чем необ- } \\
\text { ходимо }\end{array}$} & $\begin{array}{l}\text { Система запра- } \\
\text { шивает большее } \\
\text { количество } \\
\text { воды, чем не- } \\
\text { обходимо при } \\
\text { автоматических } \\
\text { промывках }\end{array}$ & $\begin{array}{l}\text { Срабатывает } \\
\text { датчик ниж- } \\
\text { него уровня } \\
\text { жидкости при } \\
\text { промывках и } \\
\text { автоматически } \\
\text { заполняется } \\
\text { танк }\end{array}$ & $\begin{array}{l}\text { Расположение } \\
\text { датчика нижне- } \\
\text { го уровня нахо- } \\
\text { дится на уровне } \\
\text { заполненного } \\
\text { танка }\end{array}$ & $\begin{array}{l}\text { Некорректно } \\
\text { установленный } \\
\text { датчик постав- } \\
\text { щиком оборудо- } \\
\text { вания }\end{array}$ & \\
\hline & $\begin{array}{l}\text { Система за- } \\
\text { правшивает } \\
\text { дополнительную } \\
\text { промывку }\end{array}$ & $\begin{array}{l}\text { Система иденти- } \\
\text { фицирует, что на } \\
\text { верхних стенках } \\
\text { танков остались } \\
\text { загрязнения }\end{array}$ & $\begin{array}{l}\text { Промывка верх- } \\
\text { них частей танка } \\
\text { произошла неэ- } \\
\text { ффективно }\end{array}$ & $\begin{array}{l}\text { Отверстия в } \\
\text { форсунках для } \\
\text { промывки танка } \\
\text { направлены } \\
\text { только в ниж- } \\
\text { нюю часть танка }\end{array}$ & $\begin{array}{l}\text { Некорректная } \\
\text { форма форсунок }\end{array}$ \\
\hline
\end{tabular}


была наибольшей и составляла 5\% от общего потребления предприятия (Табл. 1).

Как видно из Таблицы 1 у повышенных потерь воды при промывках оборудования две корневые причины, а именно некорректно установленный, поставщиком оборудования датчик нижнего уровня жидкости, а также неэффективная форма форсунок для промывки оборудования. По предложению авторов было изменено положение датчика нижнего уровня жидкости, что привело к сокращению потерь с 15\% до $7 \%$. Более того была разработана и применена новая форма форсунки, что позволило сократить потери воды с $5 \%$ до 2\% для 1 технологии из трех.

В связи с тем, что эффект от внедренных изменений совпал с планируемым результатом, а потери воды в системе фильтрации наибольшие, авторы внедрили регулярные проверки эффективности работы «обратного осмоса» с применением расходомеров воды каждые 5 месяцев и обязательную чистку мембран по прохождении $25000 \mathrm{~m}^{3}$, как стандарт на предприятии. Что касается потерь воды при промывках оборудования, новое положение датчика нижнего уровня жидкости было внесено в технологическую схему, а новая форма форсунок стала обязательным стандартом для всего применяемого на предприятии оборудования.

В рамках шестого шага было идентифицировано, что изменение положения датчика, а также новая форма форсунки применимы для всех технологий, что позволило получить общее сокращение потерь воды в 15\%. Также авторы в рамках данного шага определили, что в дальнейшем необходимо применить методику сокращения потерь воды на данном промышленном предприятии для следующего по приоритету потребителя, а именно «хозяйственно-бытовых нужд предприятия».

Таким образом, разработанная авторами методика сокращения потребления воды с учетом технологических особенностей предприятия позволила для промышленного предприятия в Санкт-Петербурге снизить потери на $15 \%$, что в денежном эквиваленте составило 13 тысяч Евро в год, при единовременных затратах в 3 тысячи Евро в ценах 2019 года [7]. Проведение анализа и внедрения мероприятий заняло 4 месяца.

\section{Библиографический список}

1. https://www.gks.ru/storage/mediabank/ohrana_2018.pdf (стр 68)

2. https://www.sakhvodokanal.ru/index.php/pressa/dlya-shkolnikov/ekonomnyj-dom/477-dlya-chegoneobkhodimo-ekonomit-vodu

3. https://www.kpms.ru/Implement/Qms_Five_Whys.htm

4. https://donpi.ru/samorazvitie/metod-isikavy-opredelenie-i-primer-postroeniya-diagrammy.html

5. http://caramboli.ru/?p=481

6. https://cyberleninka.ru/article/n/osobennosti-ochistki-stochnyh-vod-ot-dvuhvalentnyh-metallovvysokonapornym-obratnym-osmosom

7. http://www.vodokanal.spb.ru/dlya_abonentov/tarify1/ 